\title{
Attitudes of Iranian Male University Students Toward Sport and Exercise with Reference to Age, Educational Level, and Field of Study
}

Authors' contribution:

A) conception and design of the study

B) acquisition of data

C) analysis and interpretation of data

D) manuscript preparation

E) obtaining funding

\section{Hamidreza Mirsafian}

University of Isfahan, Iran

\section{ABSTRACT}

This article aimed to discover the attitudes of Iranian male university students toward sport and exercise. This study is based on the same research as another published paper regarding the attitudes of Iranian female students toward sport and exercise. Participants $(\mathrm{N}=821)$ were selected from different educational levels and fields of study from among 12 public universities. Data were collected by a modified and developed version of Kenyon's scale (1968), which measures the attitudes of people toward physical activity. For the analysis of the data, independent sample t-test and multivariate analysis of variance (MANOVA) were employed ( $\mathrm{p} \leq$ $0.05)$. The results indicated that the attitudes of the respondents can be identified as fitness $(3.96 \pm 1.02)$, catharsis $(3.84 \pm 0.80)$, social $(3.82 \pm 1.10)$, aesthetic $(3.03 \pm$ $1.14)$, vertigo $(2.15 \pm 1.16)$, and ascetic $(2.07 \pm 0.79)$. Furthermore, it was found that various demographic and social characteristics affected participants' attitudes toward sport and exercise $(\mathrm{p} \leq 0.05)$. Based on the results, it was concluded that the sport programs should be organized around students' dominant attitudes toward regular activities. In addition, planning and organizing sport programs with regard to the wide attitudinal differences between male and female students could be a big step toward improving students' participation rate in sporting activities at Iranian universities.

KEYWORDS study, constraint

\section{Introduction}

Regular activity is an essential part of a healthy lifestyle. In spite of a general agreement with this concept, many societies are still confronted by a lack or shortage of physical activity among various groups of people (Mozafari et al., 2010). Recent findings have indicated that regular activity has positive effects on people over the course of their lives with regard to their physical, psychological, and social aspects, and is an effective tool for promoting quality of life (Kamarudin \& Fauzee, 2007). Research has shown that attitudes of people may have various effects on their perceptions of sporting activities and that these attitudes and 
perceptions may affect their behavior (Zimbardo \& Leippe, 1991). Also, beliefs can determine attitude; attitude, positive or negative, can affect behavior (Ajzen, 2005; Carlson, 1995; Silverman \& Subramaniam, 1999). In other words, trends in people's decision-making processes regarding participation in regular activity are affected by their attitudes towards sport (Deflandre et al., 2004).

Having various social classes in society with positive attitudes towards regular activities leads to an increase in a tendency towards sport participation and its preservation as a considerable part of people's lifestyles (Mozafari et al., 2010). Therefore, recognizing the beliefs, needs, and attitudes concerning sport and exercise is an effective step in increasing participation in those activities.

Different groups have various attitudes toward participating in sport. These include, for instance, passing the time, therapeutic benefits, social control (Garcia et al., 2009), having fun and experiencing joy (Bernstein et al., 2011), perfect body shape and good appearance (Tergerson \& King, 2002), improving health and fitness, experiencing joy, social interaction (Attarzadeh \& Sohrabi, 2007; Liu et al., 2008; Mozafari et al., 2010) as well as increased social relationships and self-esteem (Dorak, 2011; Mozafari et al., 2010; Snyder \& Spreitzer, 1977), which have been reported as being significant regarding areas of attitudes toward participation in sporting activities.

Assessing individuals' attitudes in adolescence has special importance because their attitudes develop. In addition to formation, the result of their permanent changes is demonstrated in adulthood (Schutz et al., 1985). University students are one of the groups considered important by the researchers in studying attitudes toward sport and exercise (Safania, 2001).

Students had moderately positive attitudes toward physical education and sport (Mohammad et al., 2011). Also, maintaining good health and physical condition, getting regular exercise, developing and maintaining sound and proper physical functioning (Yoh, 2009), making one's body fit, improving one's sport skills (Safania, 2001), improving strength, mental health, joy, and reducing stress and anxiety (Kamarudin \& Fauzee, 2007), and also preventing conditions that result in physical inactivity (Gnanendran et al., 2011) are some of the attitudes students hold toward sporting activity.

Atarzadeh and Sohrabi (2007) indicated that gender, age, marital status, family size, and educational level are important factors that affect the attitudes of Iranian citizens toward sport. Clement et al. (2009) in their research carried out in the United States revealed that males have more positive attitudes than females toward physical activity that give them risk-taking experiences, whereas females are more positive than males regarding sporting activity with beautiful and graceful movements. Having a strong body and reducing stress were found to be the attitudes of male students in Malaysia, whereas improving mental health and experiencing joy were reported by females in that country (Kamarudin \& Fauzee, 2007). Huddleston et al. (2002) reported that improving health and fitness, having fun and joy, increasing social interaction, experiencing challenge achievement, having a good appearance, and experiencing competition were ranked, respectively, as leading students' attitudes towards participation in physical education, health, and leisure services in the United States. They also indicated that male students had more positive attitudes than females in challenging achievements, and obtaining fun and joy; female students were higher in competition. In contrast, Mirsafian et al. (2013a) found that the attitude of Iranian female students towards sport and exercise is negative. Indeed, sporting activities in their opinion were prolonged, hard, and had strenuous training (ascetic). Sport and exercise as tools for improving health and fitness were second. Improving social interaction and communication with others was the third most important factor determining Iranian female students' attitudes toward sporting activities.

Sallis (1993) and Trost et al. (2002) reported that the positive attitudes of American and Australian university students towards regular activities decrease with increased age. In other studies, male students reported having positive attitudes toward sporting activities that bring them risk-taking experiences (Colley et al., 1994; Hicks et al., 2001). Also, sophomores in the United States reported having positive attitudes towards regular activity over their entire lives; graduate students were more positive than other students 
towards social development (Yoh, 2009). However, in another study, the level of education did not have an impact on the attitudes of Polish citizens toward sport and exercise (Tomic, 2008).

The attitudes of university students towards sporting activities in some developing countries are dramatically based on students' gender. In fact, various cultural, traditional, and social limitations affect students' beliefs, norms, and attitudes in their everyday lives in general and in sporting behavior in particular (Mirsafian et al., 2013a). Undoubtedly, Iran is a country in which the aforementioned factors deeply affect perceptions about physical activity and sport. Various studies have indicated that the motivation of university students towards regular activity as well as their sporting behavior varies according to their gender (Ramezaninejad et al., 2010). Indeed, male students in Iran receive more encouragement to participate in regular activities for improving physical and mental health and having a fit body. However, female students were involved in sport with just the aim of spending their leisure time and being with friends (Mirsafian et al., 2013b). On the other hand, female students in Iran in general and at Iranian universities experience higher constraints on being involved in sport. The results of various studies have indicated that female students perceived higher intrapersonal (psychological factors), social (interpersonal interactions), and structural barriers (facilities, equipment, money, time) than male students regarding being involved in sporting activities (Ehsani, 2007; Mirsafian, 2014). Therefore, distinguishing university students' attitudes toward sport and exercise and finding the differences between them based on their gender are very important. Recently, the author measured the attitudes of Iranian students toward sport and exercise. One part of his research is already published and refers to the attitudes of Iranian female university students towards sport and exercise. In this article, he planned to report another part of his study regarding the attitudes of Iranian male students toward sporting activities. Hence, the objectives of this research are similar to the objectives of the other part of this study.

\section{Objectives:}

1. What are the attitudes of Iranian male students toward sport and exercise?

2. What is the relationship between students' attitudes toward sport and exercise and their ages?

3. What is the relationship between students' attitudes toward sport and exercise and their level of education?

4. What is the relationship between students' attitudes toward sport and exercise and their field of study?

\section{Materials and Methods}

\section{Participants}

This cross-sectional study was conducted among all of the full-time male students attending the range of Tehran's public universities $(n=12)$. Respondents $(N=821)$ from the age range of $18-37$ years $($ mean $=$ 25.2; $\mathrm{SD}=4.7)$ were selected by random sampling and came from three educational levels: BSc $(n=436$, $53 \%)$, MSc $(n=246,30 \%)$, and $\mathrm{PhD}(n=139,17 \%)$ and five fields of study: natural science $(n=188,23 \%)$, human science $(n=211,26 \%)$, technical science $(n=174,21 \%)$, medical science $(n=158,19 \%)$, and art $(n$ $=90,11 \%)$. The sample of this study represents fairly the total population according to the university participants studying there, their educational levels, and their fields of study.

\section{Instruments and measurements}

A corresponding self-administrated questionnaire with two distinct parts based on the aim of study was created. Demographic information (e.g., age, level of education, field of study) was requested in the first part. In the second part, a modified and developed version of questionnaire on attitudes toward physical 
activities (ATPA) was used (Kenyon's, 1968). This scale includes six dimensions and measures the attitudes of people toward physical activity (Table 1).

Table 1. Definitions of attitudinal dimensions

\begin{tabular}{ll}
\hline Dimension & Definition \\
\hline Social & $\begin{array}{l}\text { Physical activities as a social experience. Sport, games, and other forms of physical } \\
\text { recreations whose primary purpose is to provide opportunities for social participation; } \\
\text { that is, to meet new people and to continue personal friendships. }\end{array}$ \\
\hline Fitness & $\begin{array}{l}\text { Physical activities for health and fitness. Participating in physical activities primarily } \\
\text { to improve one's health and physical fitness. }\end{array}$ \\
\hline Vertigo & $\begin{array}{l}\text { Physical activities as a thrill but involving some risk. Activities that provide some } \\
\text { risk to the participant such as thrills and excitement through speed, acceleration, } \\
\text { sudden change of direction, and exposure to dangerous situations. }\end{array}$ \\
\hline Aesthetic & $\begin{array}{l}\text { Physical activities as beauty in human movement. Activities which are thought to } \\
\text { possess beauty or certain artistic qualities such as ballet, gymnastics, or figure } \\
\text { skating. }\end{array}$ \\
\hline Catharsis & $\begin{array}{l}\text { Physical activities for the release of stress and tension. The participation in physical } \\
\text { activities to get away from the problems of modern living; to provide a release from } \\
\text { "pent up emotions." }\end{array}$ \\
\hline Ascetic & $\begin{array}{l}\text { Physical activities as prolonged and strenuous training. Activities which require long } \\
\text { periods of strenuous and often painful training, which involve stiff competition and } \\
\text { demands that the individual give up a number of pleasures for a period of time. }\end{array}$ \\
\hline Source: Armation
\end{tabular}

Source: Armstrong (1993).

ATPA was previously employed in several research studies (Clement et al., 2009; Liu et al., 2008; Matthys \& Lantz, 1998; Mirsafian et al., 2013a; Mozafari et al., 2010). The internal reliability of ATPA ranged from 0.72 to 0.89 (Kenyon, 1968).

The following procedures were used to develop the questionnaire. First, in order to translate the questionnaire, three independent translators were asked to translate it into Persian. A panel of bilingual individuals critically reviewed these translations and agreed on a unified Persian version of the questionnaire that was translated back into English. The researchers then compared this back-translated English version with the English source version of the questionnaire. The two versions of the English questionnaire achieved a high level of consistency and provided support for the conceptual equivalence of the questionnaires (Alonso et al., 1990).

To ensure a high level of content validity, the questionnaire was extensively reviewed by professionals from the fields of sport pedagogy, sport management, and sport psychology $(n=9)$. Some items were removed and other items were modified based on their advice. It was then subjected to a pilot study with a sub-sample of 50 university students in different educational levels and fields of study in order to test the items for clarity and accuracy as well as to test the feasibility of the questionnaire. The modified form of the questionnaire consists of 48 items with eight items in each of the aforementioned dimensions. The internal reliability of this questionnaire is fixed between 0.79 and 0.82 (social $=0.81$, fitness $=0.82$, vertigo $=0.81$, aesthetic $=0.82$, catharsis $=0.79$, and ascetic $=0.80$ ). Participants were asked to respond to the questionnaires on a 5-point Likert scale ranging from 5, strongly agree, to 1, strongly disagree. 


\section{Procedures}

Data collection was conducted with assessment of university managers in each of the following universities for a 4-week period; Allameh Tabatabai, Amir Kabir, Kharazmi, K. N. Toosi, Shahid Beheshti, Shahid Beheshti Med Sci, Shahid Rajaee, Sharif, Tarbiat Modares, Tehran, Tehran Art, and Tehran Med Sci. Two classes of students were selected from each faculty according to the appropriate educational levels (BSc, MSc, $\mathrm{PhD}$ ) in every participating university. After obtaining permission from the particular lecturers before starting each class, students were taken to a quiet room, where they received an explanation on how to complete the questionnaire. They were given the opportunity to clarify doubts and unlimited amount of time to complete the questionnaire. Students required 15 to 20 minutes to complete the questionnaires. The process culminated in 944 questionnaires being handed out with $87 \%$ returned completed.

\section{Statistical Analyses}

Descriptive statistics and independent sample $t$-test were used to compare the attitudes of the participants to sport and exercise. Also, multivariate analysis of variance (MANOVA) was used to compare the attitudes of students regarding demographic characteristics (age, educational level, and field of study) ( $p$ $<0.05)$. For data analysis, the IBM SPSS Statistics 19 was employed.

It should be noted that the method employed in this research, as well as sampling, theoretical background, instrument, procedure, statistical analysis, and participants' characteristics (e.g., age, level of education, field of study), are completely similar with the other part of this research, which is already published, regarding the attitude of female Iranian students toward sport and exercise. Also, measuring the attitudes of male and female students expressed at the same time.

\section{Results}

The results of this study indicated that the attitudes of Iranian male students to sport and exercise are rated as fitness $(3.96 \pm 0.80)$, catharsis $(3.84 \pm 0.67)$, social $(3.82 \pm 1.00)$, aesthetic $(3.03 \pm 0.84)$, vertigo $(2.15 \pm 0.70)$, and ascetic $(2.07 \pm 0.63)$, respectively $(p<0.05)$ (Table 2$)$.

Table 2. The attitudes of Iranian male students towards participation in sport and exercise based on demographic characteristics (mean $\pm \mathrm{SD}$ )

\begin{tabular}{llllllll}
\hline Variable & & Social & Fitness & Vertigo & Aesthetic & Catharsis & Ascetic \\
\hline Age & $\mathbf{1 8 - 2 1}$ & $4.44 \pm 1.05$ & $4.11 \pm 0.65$ & $2.33 \pm 1.17$ & $2.39 \pm 0.88$ & $3.61 \pm 0.65$ & $2.11 \pm 0.84$ \\
& $\mathbf{2 2 - 2 5}$ & $3.38 \pm 0.93$ & $3.28 \pm 1.21$ & $2.47 \pm 1.25$ & $2.93 \pm 0.93$ & $3.18 \pm 0.54$ & $2.58 \pm 0.56$ \\
& $\mathbf{2 6 - 2 9}$ & $3.58 \pm 0.99$ & $3.61 \pm 1.19$ & $1.42 \pm 0.49$ & $3.65 \pm 1.25$ & $4.02 \pm 0.63$ & $2.00 \pm 0.65$ \\
& & & & & & & \\
& $\mathbf{3 0}$ and & $3.55 \pm 0.97$ & $4.42 \pm 0.86$ & $2.42 \pm 0.23$ & $3.67 \pm 0.84$ & $4.62 \pm 0.67$ & $2.08 \pm 0.88$ \\
Educational & BSc & $4.02 \pm 1.07$ & $3.78 \pm 0.77$ & $2.87 \pm 1.05$ & $2.41 \pm 0.81$ & $3.90 \pm 0.70$ & $1.90 \pm 0.83$ \\
Level & MSc & $3.70 \pm 1.09$ & $4.10 \pm 1.20$ & $1.46 \pm 0.77$ & $3.77 \pm 1.01$ & $3.88 \pm 0.88$ & $2.40 \pm 0.65$ \\
& & & & & & & \\
& PhD & $4.00 \pm 1.14$ & $4.12 \pm 1.07$ & $2.00 \pm 1.02$ & $2.75 \pm 0.99$ & $4.00 \pm 0.88$ & $1.87 \pm 0.95$
\end{tabular}




\begin{tabular}{lcccccc}
$\begin{array}{l}\text { Natural } \\
\text { Science }\end{array}$ & $3.80 \pm 0.74$ & $4.00 \pm 0.00$ & $1.00 \pm 0.00$ & $2.85 \pm 0.51$ & $3.17 \pm 0.56$ & $2.00 \pm 0.00$ \\
$\begin{array}{l}\text { Medical } \\
\text { Science }\end{array}$ & $4.16 \pm 1.28$ & $4.85 \pm 0.35$ & $1.28 \pm 0.45$ & $2.93 \pm 0.97$ & $4.04 \pm 0.93$ & $2.57 \pm 0.73$ \\
$\begin{array}{l}\text { Technical } \\
\text { Science }\end{array}$ & $4.17 \pm 1.15$ & $3.33 \pm 0.47$ & $3.00 \pm 0.82$ & $2.00 \pm 0.00$ & $4.00 \pm 0.08$ & $1.33 \pm 0.47$ \\
Art & $3.41 \pm 0.76$ & $4.41 \pm 1.36$ & $1.81 \pm 0.77$ & $4.25 \pm 1.04$ & $3.67 \pm 0.55$ & $2.60 \pm 0.49$ \\
& & & & & & \\
\hline & $3.82 \pm 1.00$ & $3.96 \pm 0.80$ & $2.15 \pm 0.70$ & $3.03 \pm 0.84$ & $3.84 \pm 0.67$ & $2.07 \pm 0.63$
\end{tabular}

Source: own study.

$*=(\mathrm{p}<0.05)$

Results of MANOVA showed a significant multivariate effect for age, educational level, and field of study regarding students' attitudes toward sports (Wilks' $\Lambda=0.78, \mathrm{~F}(4,924)=65.99, p<0.001, \eta^{2}=0.22$ ).

\section{Differences between the Participants' Attitudes based on Age}

Regarding the age characteristic, the results indicated a significant $\mathrm{F}$ value for three attitudinal dimensions: fitness, $\mathrm{F}(2)=12.22, p<0.001, \eta^{2}=0.27$; vertigo, $\mathrm{F}(2)=7.65, p<0.001, \eta^{2}=0.17$; and ascetic, $\mathrm{F}(2)=7.87, p<0.001, \eta^{2}=0.18$. Students aged between 22-25 years showed significantly more positive attitude in vertigo $(\mathrm{F}=45.50$, mean $=2.47 \pm 1.25)$ and ascetic $(\mathrm{F}=17.80$; mean $=2.58 \pm 0.56)$, whereas students aged 30 years or older had more positive attitudes in fitness $(\mathrm{F}=53.63$; mean $=4.42 \pm$ $0.86)$ than other students $(p<0.05)$.

\section{Differences between the Participants' Attitudes based on Level of Education}

In relation to students' educational level, there is a significant $\mathrm{F}$ value for two dimensions of attitude: fitness, $\mathrm{F}(2)=66.25, p<0.001, \eta^{2}=0.13$; and vertigo, $\mathrm{F}(2)=4.20, p<0.001, \eta^{2}=0.01$. Indeed, students studying at the bachelor's level showed significantly higher attitude value in vertigo $(\mathrm{F}=261.70$; mean $=$ $2.87 \pm 1.05)$ and $\mathrm{PhD}$ students had a higher value in fitness $(\mathrm{F}=12.10$; mean $=4.12 \pm 1.07)$ than other groups $(p<0.05)$.

\section{Differences between the Participants' Attitudes based on Field of Study}

The results regarding students' fields of study indicated a significant $\mathrm{F}$ value for three dimensions of attitude, social, F (3) = 494.73, $p<0.001, \eta^{2}=0.63$; fitness, F (2) = 858.56, $p<0.001, \eta^{2}=0.66$; and aesthetic, $\mathrm{F}(4)=238.23, p<0.001, \eta^{2}=0.52$. In this regard, students who studied in the field of medical science tended to have a significantly higher value in fitness $(\mathrm{F}=180.40$; mean $=4.85 \pm 0.35)$; technical science students had a higher value in social $(\mathrm{F}=21.27$; mean $=4.17 \pm 1.15)$; and those who studied in the field of art had a higher attitudinal mean value in aesthetic $(\mathrm{F}=172.50$; mean $=4.25 \pm 1.04)$ than other students $(p<0.05)$.

\section{Discussions}

Attitudes represent a system of social values, ideas, and practices orienting individuals in their material and social world. To that extent, social representations are reflected elements of social construction which, in turn, are constantly converted into social reality and are subject to re-interpretations and reevaluations (Moscovici, 1963). Hence, the people's attitude to sport and exercise is an important element of their behavior. 
The aim of this study was to assess attitudes of Iranian male students towards sport and exercise. The results indicated that participants in general had positive attitudes towards sport for improving health and having a fit body, reducing tension and stress, and establishing social interaction, compared to other attitudinal dimensions. The first rated attitude, improving health and having a fit body, is more or less similar to the attitudinal dimension reported in previous studies (Clement et al., 2009; Huddleston et al., 2002; Kamarudin \& Fauzee, 2007; Mozafari et al., 2010; Safania, 2001; Yoh, 2009). Indeed, having a healthy body and improving fitness is one of the most prevalent aims of participating in regular activities and sport for both males and females. In contrast, the attitudes of male students in Iran are quite different from the female students' attitudes toward sport and exercise. The author and his colleagues in the other part of this research indicated that female students at the Iranian universities have negative attitude towards physical activity in their everyday lives as well as in sport and exercise (Mirsafian et al., 2013a). Indeed, the first rated attitudinal dimension reported by female students was ascetic. In other words, sport and exercise in their opinions is a hard and strenuous activity, which is not a source of pleasure. These attitudinal differences are related to various issues. In general, the attitude of Iranian society to women's sport is not positive. Indeed, old beliefs and old norms as well as old, traditional values regarding women's sport remain in the Iranian society. Also, the identification of sport as a masculine activity as well as inequality between males and females in the society might affect this issue. The policy of media in Iran also contributes to establishing the negative attitude of female students to sporting activities, because many kinds of media only support men's sport. Lack of female role models in sport is another crucial problem in Iranian society. In fact, females, especially young girls and university students, do not have any role models to admire, since the media in Iran only cover the everyday lives, training, and competitions of popular male athletes. On the other hand, most Iranian families respect the dominant old beliefs and norms rooted in Iranian culture; hence, they do not have positive attitude to women's sport. So, in the best situation they do not completely support their girls involving in sport (Mirsafian et al., 2013a). Therefore, it is not surprising that the attitude of female students toward sport and exercise is negative.

Participating in regular activities with the aim of reducing tension and stress was the participants' second ranked attitude to sport and exercise, which is rarely reported in previous studies (Kamarudin \& Fauzee, 2007). In contrast, the second highest attitude of Iranian female students to sport was improving health and fitness (Mirsafian et al., 2013a). Generally speaking, various factors affect males in Iran in general and male students in particular, which put them in stressful situations. Despite the fact that studying at the public universities in Iran is free, the overall situation of most students is not comfortable. Indeed, various social and economic problems, especially these days, make their lives hard and challenging (Dadkhah, 2006; Mirsafian et al. 2013a). Moreover, social expectations toward men in Persian culture might be another factor affecting the male students' quality of life and putting them under stress (Mansourian et al., 2007). So, participating in sport and exercise in order to reduce stress and anxiety might be one of the students' ways of overcoming, or at least reducing, their tensions.

Being involved in sporting activities with the aim of establishing social interaction was another attitudinal dimension reported by participants, which is similar to the third ranked attitude of Iranian female students toward sport and exercise (Mirsafian et al. (2013a). This result is supported by the findings of previous literature (Attarzadeh \& Sohrabi, 2007; Dorak, 2011; Garcia et al., 2009; Huddleston et al., 2002; Liu et al., 2008; Mirsafian et al., 2013a; Mozafari et al., 2010; Snyder \& Spreitzer, 1977). In general, being involved in sport provides various advantages for participants in addition to improvement of physical and mental health. Students in Iranian society, regardless of their gender, participate in sporting activities to find the opportunities to communicate more with other students, to show their abilities, share their ideas and opinions, and in general, have more social exchanges than in their ordinary lives.

Ascetic, vertigo, and aesthetic rated as the lowest participants' perceptional values, regardless of grouping, in this order. This observation might imply that vigorous intensity (hard practice) is not a priority for participants in choosing regular activities and enjoying sport with activity formats (beautiful or not). These results concur with the findings of previous studies (Attarzadeh \& Sohrabi, 2007; Clement et al., 2009; 
Garcia et al., 2009; Kamarudin \& Fauzee, 2007; Liu et al., 2008; Mozafari et al., 2010). However, being involved in sport in order to enjoy risk-taking experience is not supported by other studies. Indeed, participating in regular activities with the aim of experiencing thrills, excitement through speed and exposure to dangerous situations is one of the most favorite purposes of being involved in sport for young men and adolescents (Clement et al., 2009; Colley et al., 1994; Hicks et al., 2001). In fact, Iranian male students have other priorities for being involved in regular activities. Different socio-economic and social situations in Iran and at Iranian universities, as well as with other countries, might influence this issue. Similarly, the lowest rated attitudes of Iranian female university students were catharsis, aesthetic, and vertigo, in this order. In other words, in spite of wide attitudinal differences between male and female students in Iran, they similarly do not have a positive attitude towards engaging in sports incorporating beautiful movement as well as regular activities involving risky ones causing stress and tension (Mirsafian et al. (2013a). These results are not supported by previous studies in two aspects. On the one hand, young females mostly prefer to engage in sports that are thought of as possessing beauty or certain artistic qualities (e.g., ballet, gymnastics, or figure skating). However, it is not a priority for Iranian female students. On the other hand, vertigo is known as one of the highest rated attitudinal dimension among young males and university students. Nevertheless, it is not the reason behind Iranian male students' involvement in sport and exercise.

The results indicated a significant difference in three of the attitudinal dimensions regarding the students' age groups. The effect of the age characteristic on individuals' attitudes toward sporting activities has been indicated in various studies (Fathi, 2010). Despite the fact that participants did not show positive attitudes toward sport as a risky and excitement activity, the students aged 22-25 years reported having this attitudinal dimension higher than other participants. Furthermore, they desired to participate in regular activities in order to access a prolonged and strenuous training more than other groups. With increasing age, individuals reach their intellectual maturity; their beliefs, values, expectations and, in general, their attitudes toward life issues differ from the younger students (Mozafari et al., 2010). It is indicated that the oldest age groups ( 30 years old or older) had a more positive attitude to having a healthy and fit body and involving in regular activities than other participants.

Students were also different based on various educational levels in two attitudinal dimensions. Indeed, increasing the level of education was also shown as an effective factor for changing the attitudes of people due to different values, needs, and expectations of people in terms of their level of education (Azizi et al., 2011). The results showed that undergraduate students had more positive attitude to sports involving risky activities than other groups. Also, students who were studying for a $\mathrm{PhD}$ were reported to have more positive attitude than other participants in improving physical health and fitness. These results are consistent with the findings of Mozafari et al. (2010) and Safania (2001). In contrast, the attitudes and/or awareness of female university students related to sport do not change with the progress in their studies (Mirsafian et al. (2013a). In fact, improving the level of education and having higher knowledge and awareness even in higher educational levels could not change the attitude of female students toward sport and exercise. It is mostly related to the cultural and social factors rooted in the Iranian society, which affect the attitudes and perceptions of female students and females in general toward sporting activities in the Iranian society.

There was a significant difference in three attitudinal dimensions regarding the participants' fields of study. Students in the field of technical science had more positive attitudes than other participants toward sport as a source of social interaction. It is also found logical that students majoring in medical science were the most conscious about improving their health and fitness through being involved in sport. This finding might be related to better understanding of that group of participants regarding the effects and benefits of regular activities on the body and health, based on their field of study (Gnanendran et al., 2011). Also, those who studied in the field of art had a more positive attitude than other participants toward sport as the actions involving beautiful movements; accordingly, this attitude might be due to their field of study. These results do not support the earlier findings (Fathi, 2010).

The subject of students' attitudes toward sport and exercise can be considered from different perspectives based on various aspects of students' participation, motivations, and different reasons for taking 
part in those activities. Various differences exist between the students' attitudes indicating the various expectations and needs of participants in different groups. Thus, planning based on students' different tendencies toward sport and exercise as well as their special needs could improve the participation rate of different groups of students. Also, efforts for reducing the attitudinal differences among students by improving the information they received about the deep physical, psychological, and social advantages of physical activities might be valuable.

There are wide differences between the perceptions of male and female students in Iran. Therefore, people responsible for sport in that big country should try to reduce these attitudinal differences in general and also try to plan and organize the sport programs based on the participants' gender in particular.

Finally, with regards to the impact of youth - especially university students - on general ideas and community attitudes, the reinforcement of attitudes towards learning about and participating in regular activities could be effective in improving their attitudes.

\section{Acknowledgements}

The author wishes to express his sincere gratitude to all the participants involved in this study for their maximal effort and cooperation.

\section{REFERENCES}

Armstrong, G. (1993). Assessing changes in attitudes toward physical activity and leisure activity participation patterns of college students after a personalized health fitness course. Unpublished doctoral dissertation, New York University, USA.

Ajzen, I. (2005). Attitudes, personality, and behaviour. $2^{\text {nd }}$ ed. Milton-Keynes, England: Open University Press /McGraw/ -Hill.

Alonso, J., Anto, J.M., Moreno, C. (1990). Spanish version of the Nottingham health profile: translation and preliminary validity. American Journal of Public Health, 80(6), 704-708.

Attarzadeh, H., Sohrabi, M. (2007). Tosif negaresh va gerayesh mardom shahr Mashhad be faaliyathay harkati va varzeshi/Attitudes and tendency to exercise and sport activities in people of Mashhad/. Olympic, 15(1), 38-47.

Azizi, B., Farahani, M.J., Khabiri, M. (2011). Baresi negaresh daneshjoyan saken khabgahhay daneshgah Tehran be varzesh hamegani /Survey of the attitudes of students living in university of Tehran dormitories towards sport for all/. Sport Management, 2(8), 75-91.

Bernstein, E., Phillips, S., Silverman, S. (2011). Attitudes and perceptions of middle school students toward competitive activities in physical education. Journal of Teaching in Physical Education, 30, 69-83.

Carlson, T.B. (1995). We hate gym: Student alienation from physical education. Journal of Teaching in Physical Education, 14, 467- 477.

Clement, D., Brooks, D., Wilmoth, B. (2009). Parental attitudes towards physical activity: a preliminary analysis. International Journal of Fitness, 5(2), 1-11.

Colley, A., Comber, C., Hargreaves, D.J. (1994). Gender effects in school subject preferences: A research note. Educational Studies, 20, 13-18.

Dadkhah, B. (2006). Baresi salamat ravani daneshjoyan dar daneshgah olum pezeshki Ardebil/Survey the mental health of Ardabil medical sciences students/. Journal of Ardabil Medical Sciences University, 6(1), 31-6.

Deflandre, A., Antonini, P.R., Lorant, J. (2004). Perceived benefits and barriers to physical activity among children, adolescents and adults. International Journal of Psychology, 35:23-36.

Dorak, F. (2011). Self-esteem and body image of Turkish adolescent girls. Social behavior and Personality: An International Journal, 39(4), 553-562.

Ehsani, M. (2007). Level of sport participation for women in iran and leisure constraints. Humanities, 12(3), 1527.Fathi, S. (2010). Tabeen jame shenakhti mosharekat varzeshi daneshjooyan /A sociological explanation of athletic participation of university students/. Social Sciences Bulletin, 3(4), 145-173.

Garcia, D., Devis, J., Sparkes, A. (2009). Sport and physical activity in high security Spanish prison: ethnographic study of multiple meaning. Sport Education and Society, 14(1), 77-96. 
Gnanendran, A., Pyne, D.B., Fallon, K.E., Fricker, P.A. (2011). Attitudes of medical students, clinicians and sports scientists towards exercise counseling. Journal of Sports Science and Medicine, 10, 426-431.

Hicks, M.K., Wiggins, M.S., Crist, R.W., Moode, F.M. (2001). Sex differences in grade three students' attitudes toward physical activity. A Perceptual and Motor Skills, 93, 97-102.

Huddleston, S., Mertesdorf, J., Araki, K. (2002). Physical activity behavior and attitudes toward involvement among physical education, health, and leisure services pre-professionals. College Student Journal, 36, 555-572.

Kamarudin, K., Fauzee, M. (2007). Attitudes toward physical activities among college students. Journal of Psychological Research, 22, 43-54.

Kenyon, G.S. (1968). Six scales for assessing attitude toward physical activity. Research Quarterly, 39, $566-574$.

Liu, W., Wang, J., Xu, F. (2008). Middle school children's attitudes toward physical activity. The ICHPER SD (The International Council for Health, Physical Education, Recreation, Sport and Dance) Journal of Research, 3(2), 78-85.

Mansourian, M., Shojaeezadeh, D., Sayemiri, K. (2007) Barresi keifiat zendegi mortabet ba salamat daneshjoyan daneshgah olom pezeshki Ilam dar sal 1384/A study of the quality of students' life in the university of medical sciences of Ilam in 2005/. Toloue Behdasht, 6(2), 31-8.

Matthys, J.M., Lantz, C.D. (1998). The effects of different activity modes on attitudes toward physical activity. Iowa Association of Health Physical Education, Recreation and Dance Journal, 31(2), 24-26.

Mirsafian, H. (2014). Constraints to participation in physical activity and sport: a comparative study between Hungarian and Iranian Students. Doctoral Dissertation, Semmelweis University, Hungary.

Mirsafian, H., Doczi, T., Mohamadinejad, A. (2013a). Attitude of Iranian Female University Students to Sports and Exercise. Iranian Studies, In Press. DOI: 10.1080/00210862.2013.823790

Mirsafian, H., Mohamadinejad, A., Homaie, R., Hédi, C. (2013b). Motivation of Iranian University Students for Participation in Sporting Activities. Physical Culture and Sport Studies and Research, 59, 42-48.

Mohammad, A., Abraham, B., Singh, J. (2011). Attitude of college students towards physical education and sports. International Journal of Physical Education, 4(1), 45-52.

Moscovici, S. (1963). Attitudes and opinions. Annual Review of Psychology, 14, 231-260.

Mozafari, A., Ahani, K., Shajie, A., Hadavi, F. (2010). Tosif negaresh va gerayesh mardom be faliathai harkati va varzeshi dar jomhori eslami Iran /Attitude and tendency of people toward physical activity and sport in Islamic Republic of Iran/. Olympic, 18(1), 69-81.

Ramezaninejad, R., Rahmaninia, F., Taghavi, S.A. (2010). Baresi vaziat ejtemai eghtesadi va angizesh sherkat konandegan dar varzeshhai hamegani /Study of socioeconomic status and motives of participants in sport for all/. SportManagement, 1(2), 5-19.

Safania, A.M. (2001). Baresi vaziat oghat feraghat daneshjoyan dokhtar daneshgahai azad va naghsh varzesh dar an /Study on the leisure time of Islamic Azad University female students and the role of sports in spending such time/. Harakat, 9, 127-140.

Sallis, J.F. (1993). Epidemiology of physical activity and fitness in children and adolescents. Critical Reviews in Food Science and Nutrition, 33, 403-408.

Schutz, R.W., Smoll, F.L., Carre, F.A., Moshe,r R.E. (1985). Inventories and norms for children's attitudes toward physical activity. Research Quarterly in Exercise and Sport, 56, 256-265.

Silverman, S., Subramaniam, P.R. (1999). Student attitude toward physical education and physical activity: A review of measurement issues and outcomes. Journal of Teaching in Physical Education, 19, 97-125.

Snyder, E.E., Spreitzer, E.A. (1977). Correlates of sport participation among adolescent girls. Research Quarterly, 4, 804-809.

Tergerson, J.L., King, K.A. (2002). Do perceived cues, benefits, and barriers to physical activity differ between male and female adolescents. Journal of School Health, 72(9), 374-380.

Tomic, R. (2008). Adolescent attitudes towards sport depending on school level, gender and school sports club membership. Journal of Human Kinetics, 20, 121-130.

Trost, S.G., Russesll, R.P., Sallis, J.F., Freedson, P.S. (2002). Age and gender differences in objectively measured physical activity in youth. Medicine and Science in Exercise and Sport, 34(2), 350-355.

Yoh, T. (2009). Motivational attitudes toward participating in physical activity among international students attending colleges in the United States. College Student Journal, 43(3), 931-937.

Zimbardo, P.G., Leippe, M.R. (1991). The psychology of attitude change and social influence. New York: McGraw-Hill. (Hardcover edition: Philadelphia: Temple University Press). 
AUTHOR'S ADDRESS: Hamidreza Mirsafian

Faculty of Physical Education and Sport Sciences

Daneshgah St. University of Isfahan

Isfahan, Iran

Email: Hamid.Mirsafian@gmail.com 